\title{
Total parenteral nutrition in infancy: effect on the liver and suggested pathogenesis
}

\author{
C A HUGHES.* I C TALBOT. D A DUCKER. $\div$ AND M J HARRAN \\ From the Departments of Child Health and Pathology. University of Leicester. Clinical Sciences Building. \\ Leicester Royal lnfirmary. Leicester
}

SUMmary Biochemical. histological, and electron-microscopic investigation of seven preterm infants who became jaundiced after prolonged total parenteral nutrition showed conjugated hyperbilirubinaemia apparently due to cholestasis without significant primary liver cell injury. In the absence of evidence indicating a direct toxic effect on the liver of this form of nutrition the necropsy findings in one child and analogy with the effects of total parenteral nutrition in animals suggest that the cholestasis is the result of suppression of trophic and/or secretion-stimulating hormone(s) normally produced by the gut. due to absent enteral nutrition. Biochemical and electron-microscopic findings suggest that liver cell damage occurs after resumption of enteral nutrition.

Total parenteral nutrition is an effective method of supplying energy and nutrients to support life and growth in neonates and infants and is used when enteral feeding is contraindicated because of paralytic ileus or intestinal mucosal damage. Many problems with this type of nutrition have been described.' one of which is conjugated hyperbilirubinaemia. Babies with low birth weights (below $2.5 \mathrm{~kg}$ ) are especially liable to develop this problem. The reason is unclear but many factors have been suggested. Liver biopsies of some babies suggest that there is an inflammatory response and hepatocellular injury..$^{--}$whereas others have shown that there is predominantly an increase in bile ducts such as that seen with biliary atresia ${ }^{5}$ or a combination of these histological changes. Percutaneous liver biopsies were performed in four infants in whom the cause of conjugated hyperbilirubinaemia was unclear and immediately after death in three infants. To follow the onset. course. and progress of the liver disease. plasma activities of the enzymes alanine amino transferase and gamma glutamyl transpeptidase were measured at approxi-

\footnotetext{
Present addres: Institute of (hild Health. Francis Road. Fdghaston. Birmingham Blo SE T

Present addres: Department of Child Health. St Ceorges Hospital. Blackshau Road. Londen SWl-

- Present addres: Department of Paediatrics. York District Hospital. Wigginton Road. York YO: $7 \mathrm{HE}$

Addrew for reprint requess: Dr I C Talbot. Department of Pathologs. Clinical Scienes Building. I.cicester Roval Intirmars. PO) Box 6.5. Lecicester L.F. 7 L.X.

Received for putlication $1+$ June 1952
}

mately weekly intervals to differentiate predominantly hepatocyte damage from canalicular disease."

\section{Methods}

Seven preterm infants born at 27-33 weeks' gestation during 1978-79 who developed a persistent and prolonged conjugated hyperbilirubinaemia (serum bilirubin $>100 \mu \mathrm{m} / \mathrm{l}$ ) during or after total parenteral nutrition are reported. Percutaneous liver biopsies were performed as part of the clinical investigation of conjugated hyperbilirubinaemia.

All infants received parenteral nutrition through a central silastic catheter inserted via a peripheral vein. ${ }^{1}$ The infants received a total water intake of $60-120 \mathrm{ml} / \mathrm{kg} / \mathrm{day}$ during the first week of life and thereafter $150-180 \mathrm{ml} / \mathrm{kg} / \mathrm{day}$. L-amino acids (Vamin. 10\% glucose ${ }^{*}$ ) were started at $0.75 \mathrm{~g} / \mathrm{kg}$ body weight/day and increased to a maximum amount of $2.5 \mathrm{~g} / \mathrm{kg}$ body weight/day over at least five days. Dextrose was given as a $10 \%$ solution starting at $8 \mathrm{~g} / \mathrm{kg}$ body weight/day and increased to a maximum of $18 \mathrm{~g} / \mathrm{kg}$ body weight/day depending on tolerance. Fat was given as 10 or $20 \%$ Intralipid* by a continuous infusion over a 20 hour period each day to a maximum of $4 \mathrm{~g}$ fat $/ \mathrm{kg}$ body weight/day. Sodium and potassium were given to maintain satisfactory levels in plasma and urine. Macro- and microelements were given as formulated in Ped-El*

Kahivitrum Lid. Stockholm. Sweden. 
Vitamins were given daily in the form of MVI (USV Pharmaceutical (orp) or Solivito" and Vitlipid". Satisfactory growth was achieved on this regime of a non-protein energy intake of $(1 \cdot 38-() \cdot 46 \mathrm{MJ} \mathrm{kg} / \mathrm{body}$ weight/day (90)-110 Kcal).

Venous or arterial blood samples were taken once or twice weekly for assessment of metabolic and nutritional status and included the estimation of bilirubin, $\gamma$-glutamyl transpeptidase (GGT: EC. 2.3.2.2) and alanine amino transferase (ALAT: EC. 2.6.1.2). G(GT and ALAT were analysed on a MSE Vitatron automatic kinetic enzyme system (MSE Scientific Instruments, Crawley, England) using reagents from Smith and Kline Instrument Co Ltd (Welwyn Garden City. England). The Spin Chem GGT reagent used was a modification of the method of Szasz." The Plus (hem ALAT reagent used adopted the method of Henry et $a^{111}$ optimised at $35^{\circ} \mathrm{C}$. All assays were performed at $37^{\circ} \mathrm{C}$.

The liver biopsies were performed 10-17 weeks post-natally. after starting full enteral nutrition in four of the infants with local anaesthesia, using a Jamshidi needle and immediately after death on three infants aged 7-19 weeks. The tissue was immediately fixed in $10 \%$ formol saline for 24 hours and then processed into paraffin wax for routine histology. Sections were stained with haematoxylin and eosin, by Perls' technique and by Gordon and Sweet's silver method for reticulin fibres. Samples of five of the infants (one immediately after death) were fixed in Karnovsky's fixative ${ }^{11}$ and processed into resin for electron microscopy. One infant (JT) was rebiopsied 36 weeks after stopping parenteral nutrition, during a laparotomy performed for closure of a temporary ostomy. The liver was rebiopsied because of late appearance of the conjugated hyperbilirubinaemia and to ascertain whether there was progressive liver disease.

\section{Results}

The indications for total parenteral nutrition in the preterm infants and the age at which it was given are summarised in Table 1. The period of time after starting parenteral nutrition at which an obstructive jaundice first became apparent varied from 22 to 57 days. We have not seen conjugated hyperbilirubinaemia occurring in infants fed by this method of nutrition for a period of less than 22 days. There was no evidence of congenital infection with Toxoplasmosis, cytomegalovirus rubella, or syphilis, or post-natal infection with hepatitis B virus or cytomegalovirus and none of the babies was $\alpha-1$ antitrypsin deficient. From Table 1 it can be seen that three of the infants died from multi-organ failure. A fourth infant (EC) presented as a sudden infant death at the age of 6 months while at home.

I.ICill MIC ROSCOPY

Histological material from each child was adequate and each hiopsy showed similar features, illustrated in Fig. 1. although their severity was variable. The changes may conveniently be described separately as portal tract and parenchymal.

PORINI IRICI CHINCitS

The portal tracts were enlarged and oedematous in all the specimens examined, and proliferation of bile ductules at the periphery of the portal tracts was invariably a prominent feature. Sometimes the epithelial cells of bile ducts and ductules were irregular or distorted. Bile thrombi were observed in bile ducts or ductules in all except one patient (RC) and a periductular neutrophil exudate was a constant feature. Lymphocytes were characteristically scanty and eosinophils not usually found. In addition, there was usually an irregular extension of loose mesenchyme-like connective tissue into the periportal parenchyma but this was never florid and in no patient was there evidence of fibrosis.

\section{PARENCHYMAL CHANGES}

The parenchymal changes were predominantly those of cholestasis with bile pigment in hepatocytes and canalicular bile plugging in all biopsies: the latter was predominantly centrizonal. Kupffer cells were usually swollen and laden with bile pigment and often with haemosiderin. There was feathery degeneration of hepatocytes, particularly around the portal tracts in five of the infants $(\mathrm{RC}, \mathrm{BL}, \mathrm{EC}$. $\mathrm{JK}$, and JT). A few inflammatory cells were observed in the parenchyma in one patient only (SP).

\section{ELECTRON MICROSCOPY}

Ultrastructural examination of liver tissue from five children (Figs 2, 3) confirmed the canalicular bile plugging and showed focal loss of canalicular microvilli. The hepatocytes contained both bile and pseudobile and there was vesiculation of endoplasmic reticulum. There was also swelling. distortion of cristae, and disruption of mitochondria.

\section{NECROPSY}

Necropsy examination of the infants who died revealed small but patent extrahepatic bile ducts. The lumen of the common bile duct was blocked by plugs of dark green biliary sludge in one. The histological appearance of the liver in the three babies who died closely resembled that of the livers of those who survived. 
Total parenteral mutrition in infancy: effect on the liver and suggested pathogenesis

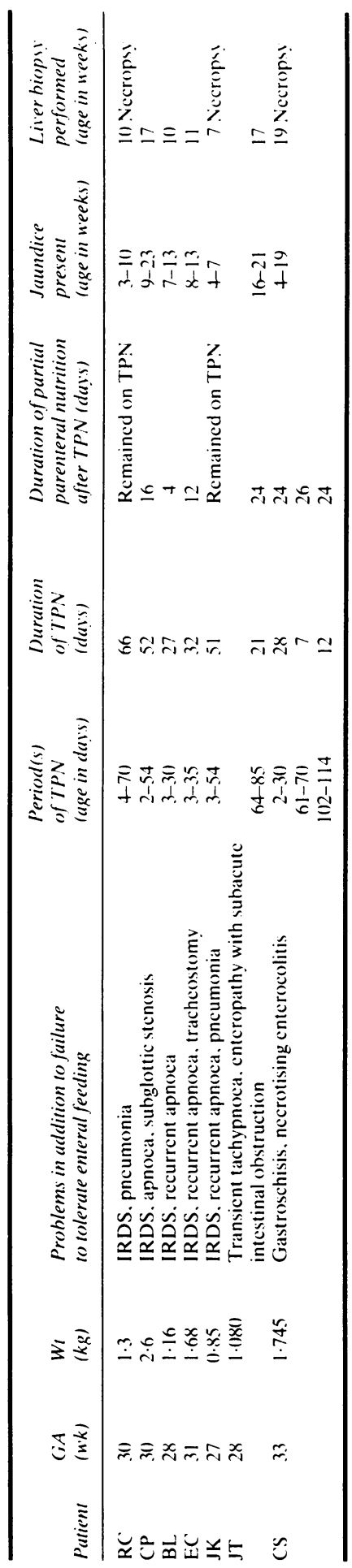


Fig. 1 Liver hiopsin of jaundiced infant $(E)$ ( ) showing portal tract enlargement due to oedema, with proliferation and epithelial distortion of bile ductules. Bile thrombi are present in bile ductules, periportal hepatocytes show feathery degeneration, and there is a neutrophil exudate around damaged periportal hepatocvtes and ductules. $H$ and $E, \times 250$ (original magnification).
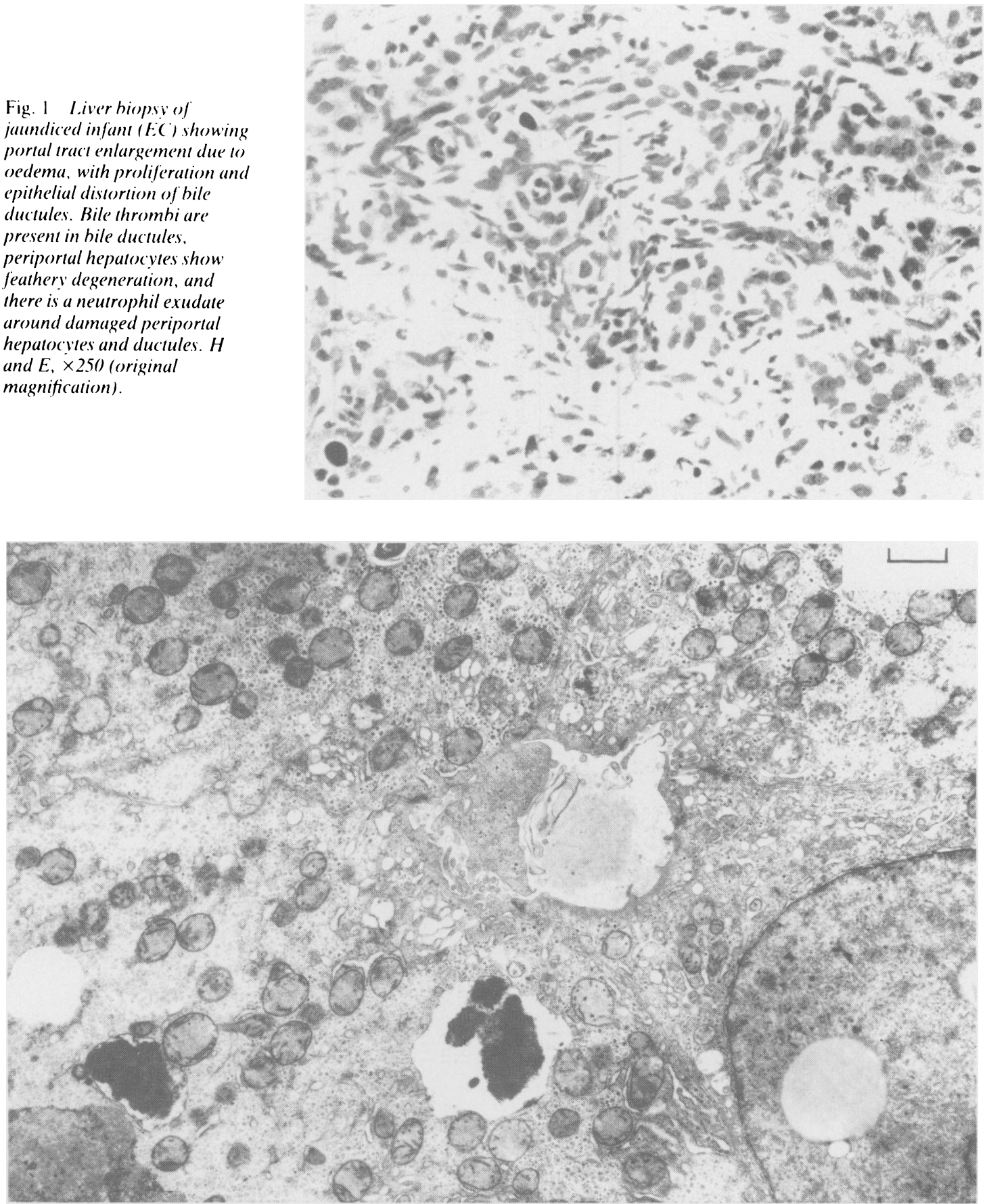

Fig. 2 Electron micrograph of liver biopsy from jaundiced infant $(B L)$. There is bile pigment in autophagic vacuoles of hepatocyte in lower half of field and laminated, whorled pseudobile at the upper edge of the field. The canaliculus (centre) is distended by faintly staining bile, contains a shed mass of finely granular ectoplasm and shows focal loss of microvilli. Pericanalicular cytoplasmic vacuoles are probably dilated endoplasmic reticulum. Mitochondria show variable distortion and disruption. (Scale mark $=1 \mu \mathrm{m}$.) 


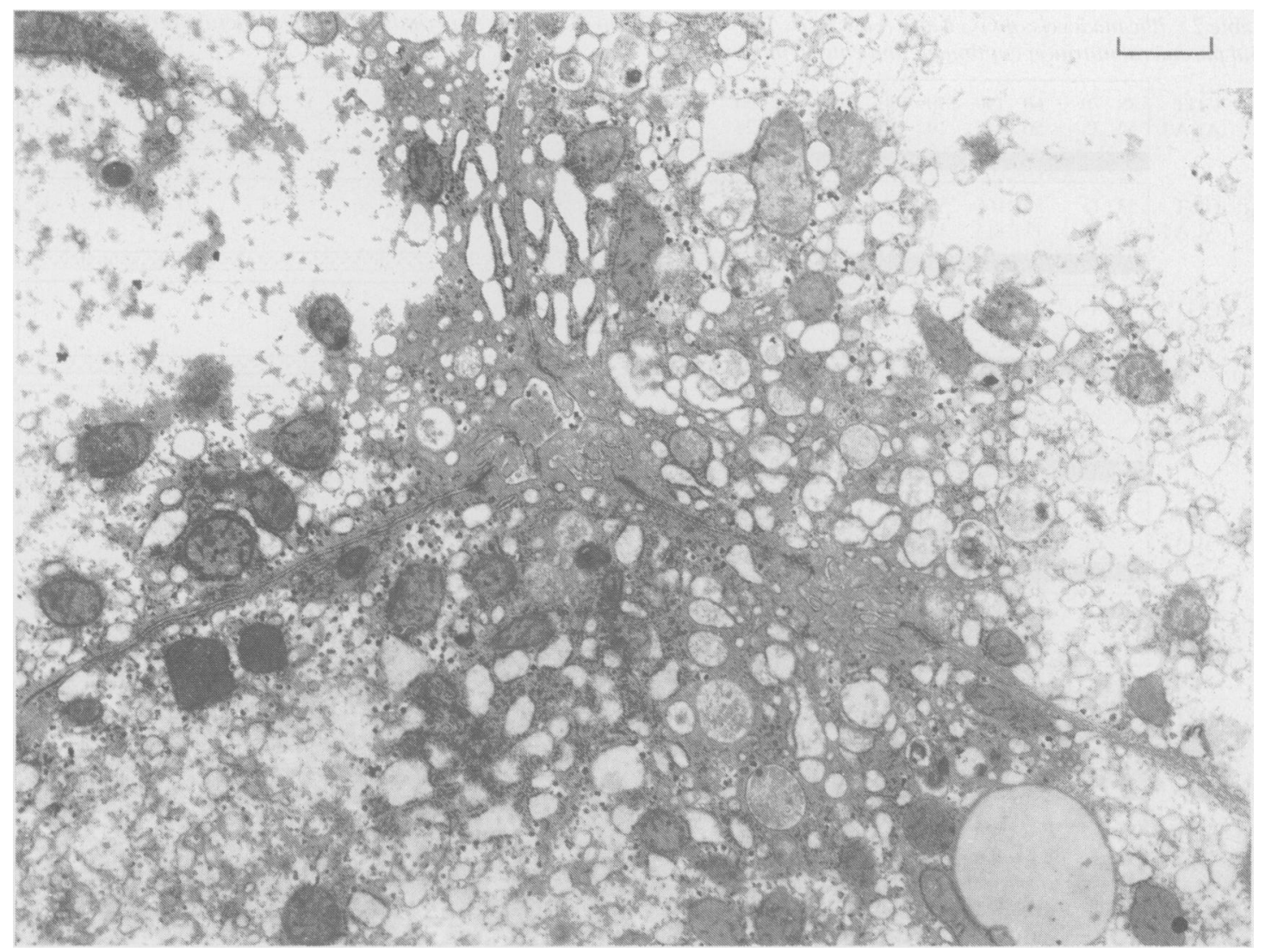

Fig. 3 Electron micrograph of liver biopsy from infant (JT), clinically recolered from jaundice and 36 weeks after total parenteral nutrition. The bile canaliculi have reverted to a more normal morphology but the cytoplasmic organelle changes persist and damaged mitochondria and vesiculation of endoplasmic reticulum are more prominent. (Scale mark $=1 \mu m$.)

FOLLOW-UP BIOPSY

A follow-up liver biopsy in one of the children (JT) taken nine months after total parenteral nutrition was discontinued showed complete resolution of the portal tract abnormalities and the liver was essentially normal apart from some residual parenchymal cholestasis. The bile canaliculi were normal at electron microscopy but there was more severe damage of hepatocyte organelles, there being considerable swelling and disruption of mitochondria and vesiculation of endoplasmic reticulum.

\section{PI.ASMA ENZYMES}

The results for GGT and ALAT are shown in Table 2. The reference values for ALAT in neonates in our clinical chemistry laboratories are given. The normal range for GGT in premature neonates is not known, but in six of the infants it became increasingly raised and returned to a low level eight to 16 weeks after parenteral nutrition ended. On the other hand, ALAT did not start to rise until enteral feeds were introduced.

Serum alkaline phosphatase, although raised, was found to be predominantly of bone type and was not therefore used in these children as a marker of hepatobiliary dysfunction. Bilirubin was measured routinely only after the patients became clinically jaundiced and was predominantly conjugated.

\section{Discussion}

These studies of plasma enzyme activities and liver histopathology suggest that the jaundice which occurs in association with total parenteral nutrition is due to a failure of bile secretion or excretion rather than primarily hepatocellular injury. The cholestasis occurs within two to four weeks of 
Table 2 Plasma levels of GG;T and ALAT IIU/l) for e'ach patient in relation to periods of total parenteral nutrition, enteral and parenteral mutrition combined, and enteral nutrition alone'

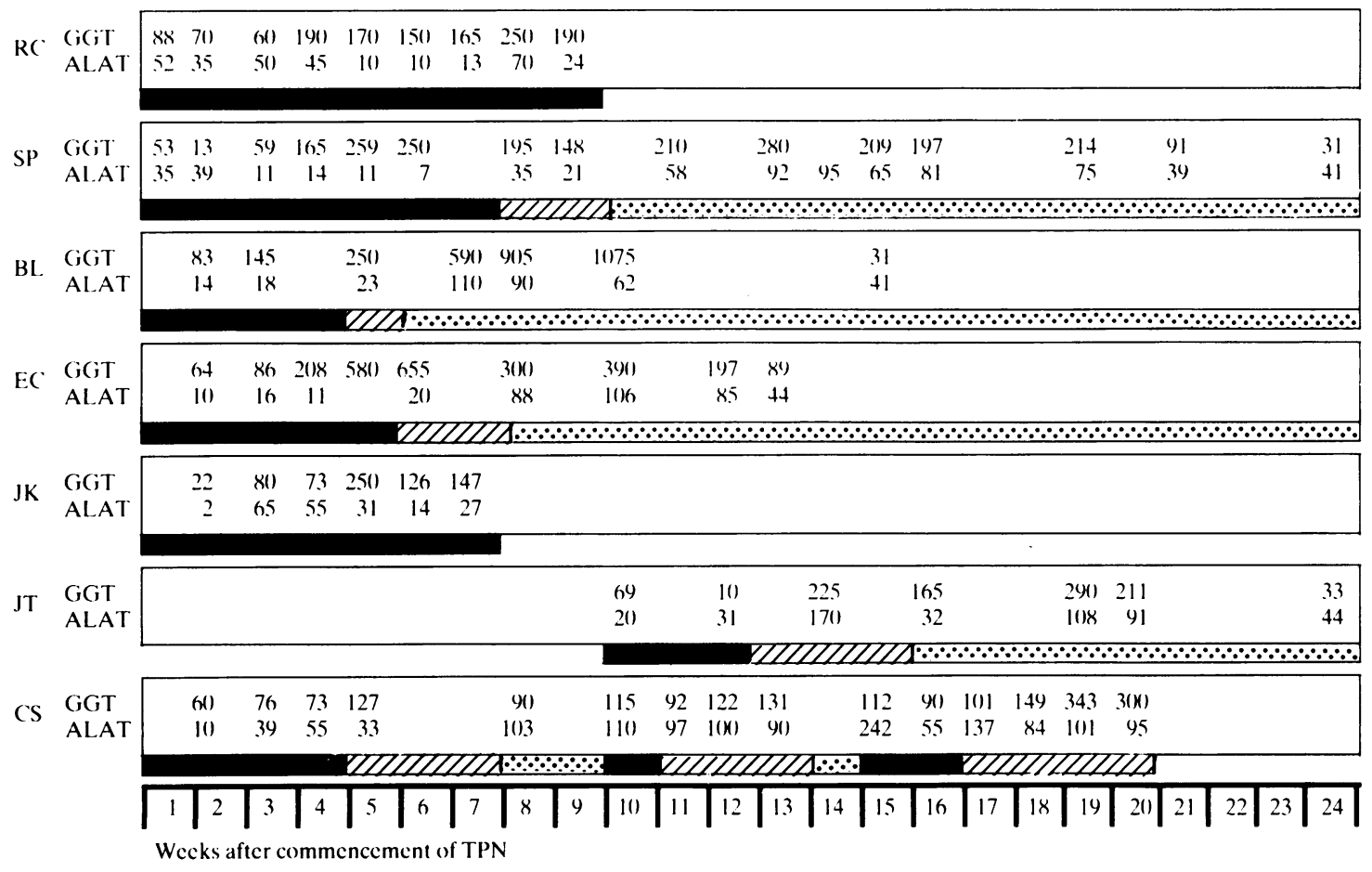

Total parenteral nutrition for ALAT in neonates: $2-77 \mathrm{IU} / \mathrm{I}$.

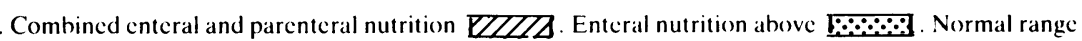

starting this form of nutrition and resembles mechanical bile duct obstruction. ${ }^{12}$ Furthermore, we have not been able to identify any particular organelle damage which could have been caused by a constituent of the parenteral fluids; the ultrastructural features are non-specific and resemble those documented in association with cholestasis due to a variety of causes. ${ }^{13}$

The rise in plasma enzyme activity which occurred shortly after the introduction of enteral nutrition suggests that damage to hepatocytes may be the result of the resumption of bile flow; whether this results from loss of integrity of pericanalicular tight-junctions between hepatocytes which have atrophied after total parenteral nutrition, thereby allowing regurgitation of bile from canaliculi between the hepatocytes, which thereby become damaged, must remain speculative after this investigation.

BIOCHEMICAL PARAMETERS STUDIED

Plasma activities of GGT and ALAT were assayed as markers of cholestasis and hepatocellular damage respectively. ${ }^{x}$ Although little is known about the significance of absolute levels of GGT in premature infants, ${ }^{14}$ it is clear that there was a rise in GGT activity within two to four weeks of parenteral nutrition in our infants. This corresponds with the rise in serum conjugates of cholic acid after two weeks' total parenteral nutrition in the babies described by Sondheimer et al whose birth weight was less than $2 \mathrm{~kg}^{15}$ There is therefore good biochemical evidence that cholestasis occurs at an early stage during total parenteral nutrition.

\section{CHOLESTASIS AND HEPATOCELLULAR INJURY}

The histological and ultrastructural appearances and plasma enzyme activities suggest that the hepatocyte is spared injury, at least during total parenteral nutrition. Only after starting enteral nutrition was there evidence that hepatocyte damage might be occurring, shown by the rise in plasma ALAT activity. Although this injury was not obvious on light microscopy, ultrastructural examination of the liver in these infants and in those studied previously ${ }^{3}$ shows evidence of hepatocyte damage, still present 
in one infant 36 weeks after total parenteral nutrition was discontinued (Fig. 2).

Previously reported histological features have included necrosis and ballooning degeneration of some hepatocytes ${ }^{2} 7$ and giant cell transformation. ${ }^{3}$ These infants received total parenteral nutrition for feeding intolerance associated with respiratory distress. ${ }^{2}$ volvulus or duodenal stenosis. ${ }^{7}$ or necrotising enterocolitis. ${ }^{3}$ Cholestasis, with bile retention and bile duct proliferation. but little or no evidence of hepatocellular damage has. however. been reported by others ${ }^{+1} 1617$ and in some cases these changes have been associated with a periportal inflammatory response. ${ }^{+6} 16$ Ultrastructural examination of the liver in these infants and others, ${ }^{3}$ however. shows, in addition to the features of cholestasis, evidence of damage to the hepatocytes. We do not know if these changes were present before enteral feeds were introduced.

Doubt has been cast on the relationship between the severity of the pathological findings and duration of total parenteral nutrition. ${ }^{6}{ }^{18}$ but recently Cohen and Olsen ${ }^{5}$ have shown that liver pathology develops sequentially in infants receiving long-term total parenteral nutrition.

LONG-TERM RESULTS

The infants described in this paper showed no evidence of fibrosis, although this has been described in other series. ${ }^{+6} 18-20$ Indeed, a few patients have progressed to cirrhosis, ${ }^{521} 22$ but only after receiving total parenteral nutrition for from 179 to 300 days. Although such prolonged periods may increase the severity of the liver damage. abdominal sepsis and ascending cholangitis seem to have contributed to the problem in these cases. ${ }^{5} 2122$ Long-term follow-up is required if the ultrastructural changes are to be fully evaluated.

\section{AETIOLOGY OF CHOLESTASIS}

This does not appear to be related to the constituents of the fluid given intravenously, whether L-amino-acids, protein hydrolysates, or intravenous fat emulsion are included. ${ }^{19}$ It may be significant that cholestasis has been observed in infants not given any of these nutrient mixtures but who have not been given food enterally ${ }^{23}$ in the course of management of a variety of gastrointestinal problems. Deficiency of a specific amino acid essential to the formation of normal bile salts, ${ }^{7}$ an increase in the lithogenicity of bile, interference with micelle formation and the flow of bile into the canaliculus, or interference with hepatobiliary enzymes controlling bile secretion ${ }^{2+}$ have all been suggested as possible aetiological factors. Other postulated aetiological factors are hyperammon- aemia. ${ }^{25}$ inbalances of plasma amino acids, ${ }^{14} 22$ sepsis." toxicity from tryptophan conversion products. ${ }^{26}$ or peptide hydrolysates. ${ }^{3}$ The problem is increased by high protein and dextrose intakes. ${ }^{27}$

\section{ABSENT ENTERAL NUTRITION}

Rager and Finegold ${ }^{h}$ suggested that early fasting rather than parenteral supplementation may contribute to impaired hepatobiliary function in the small premature infant. Certainly in animals fed parenterally which do not receive any nutrients by the enteral route (other than endogenous secretions) both the intestinal mucosa ${ }^{2 x}$ and pancreas $^{29}$ become atrophic. It would not be unreasonable to suggest that the hepatobiliary system is similarly affected, with the bile ducts and canaliculi becoming arrested in their development or atrophic. The mechanism whereby such changes occur is speculative but the release of gastrointestinal hormones with trophic and/or secretory action on the hepatobiliary system may be reduced because of absent enteral nutrition. There is indirect evidence for this hypothesis in that the pancreatic atrophy which developed in parenterally fed rats was completely prevented by daily infusions of cholecystokinin-octapeptide. ${ }^{30}$ Although this applies to animals, the same phenomenon is likely to be seen in neonates and suggests that hormones normally released by enteral nutrition are responsible for maintaining the structure and function of digestive organs. It is probable that cholecystokinin and related hormones also stimulate bile secretion in the ducts and ductules. ${ }^{32}$ Diminished secretion of these hormones would lead to a decreased secretion of bile with increased viscosity and the formation of bile plugs. This problem may be further enhanced by the functional immaturity of the liver. ${ }^{33}$ In addition, the composition of bile may be altered by the nutrients used in total parenteral nutrition, so that it becomes more lithogenic, as has been shown in rats. ${ }^{34}$

This complication of parenteral nutrition in neonates, particularly those born before term, is related to the duration of the parenteral nutrition. The cause may be multi-factorial but lack of enteral nutrition with suppression or lack of hormone stimulation should be considered as a possible relevant factor. We think that it is important that enteral feeding should be started as soon as possible to stimulate the flow of hepatobiliary secretions that might be important for the normal development of the bile excretory system.

We also believe that insufficient attention has been given to this pathogenetic mechanism as a cause of the jaundice often seen in fasted adult patients in intensive care units, when lack of enteral 
nutrition may have an additive effect on a liver already subjected to hypoxic and other damaging influences.

We thank Dr D P Davies for allowing us to study patients under his care. Dr T J Davies for estimating the enzyme activities, and Mrs G Holmes for typing the manuscript.

\section{References}

1 Hughes ( A. Parenteral nutrition in preterm infants personal practice. In: Wharton BA, ed. Topics in perinatal medicine 2. London: Pitman. 1982: 87-102.

2 Beale EF. Nelson RM. Bucciavelli RL. Donnelly WH. Eitzman DV. Intrahepatic cholestasis associated with parenteral nutrition in premature infants. Pediatrics 1979: 64: 342-7.

3 Bernstein J. Chang $\mathrm{CH}$. Brough AJ. Heidelberger KP. Conjugated hyperbilirubinaemia in infancy associated with parenteral alimentation. J Pediatr 1977; 90: 361-7.

4 Rodgers BM. Hollenbeck JI. Donnelly WH. Talbert JC. Intrahepatic cholestasis with parenteral alimentation. Am J Surg 1976; 131: 149-55.

5 Cohen CC. Olsen MM. Pediatric total parenteral nutrition. Arch Pathol Lab Med 1981: 105: 152-6.

6 Rager R. Finegold MJ. Cholestasis in immature newborn infants: is parenteral alimentation responsible? J Pediatr 1975: 86: 264-9.

7 Touloukian RJ. Downing SE. Cholestasis associated with long-term parenteral hyperalimentation. Arch Surg 1973; 106: 58-62.

8 Schmidt FW. Enzymes in cholestasis. In: Bianchi G. Gerok W. Sickinger K, eds. Liver and bile. Lancaster: MTP Press, 1977: 203-14.

9 Szasz G. A kinetic photometric method for serum a glutamyl transpeptidase. Clin Chem 1969; 15: 124-36.

10 Henry RT. Chiamori N. Goluk OJ. Berkman S. Revised spectrophotometric methods for the determination of glutamic-oxalo-acetic transaminase. glutamic pyruvic transaminase and lactic acid dehydrogenase. Am J Clin Pathol 1960); 34: 381-98.

11 Karnovsky MJ. A formaldehyde-gluteraldehyde fixative of high osmolality for use in electron microscopy. J Cell Biol 1965; 27: 137A-8A.

12 Patrick RS, McGee JO'D. In: Biopsy pathology of the liver. London: Chapman and Hall, 198(): 115.

13 Desmet VJ. In: MacSween RNM. Anthony DP. Scheuer PJ, eds. Pathology of the liver. Edinburgh. London. and New York: Churchill Livingstone. 1979: 277-83.

14 Rosalki SB. Gamma-glutamyl transpeptidase. In: Advances in clinical chemistry. New York and London: Academic Press. 1975: 68.

15 Sondheimer JM, Bryan H, Andrews W. Farstner GG. Cholestatic tendencies in premature infants on and off parenteral nutrition. Pediatrics 1978; 62: 984-9.

16 Touloukian RJ. Seashore JH. Hepatic secretory obstruction with total parenteral nutrition in the infant. J Pediatr Surg 1975: 10: 353-60).
17 Zarid MA. Pildes RS. Szanto PB. Vidvasagor D). (holestasis associated with administration of L-amino acids and dextrose solutions. Biol Neenate 1976: 29: 6or-76.

Is Dahms BB. Halpin TC'. Serial liver biopsics in parenteral nutrition - associated cholestasis of carly infancs. (Abstract.) lab Invest 1980): 42: 17(1-1.

19) Postuma R. Trevenen (1. Liver disease in infants receiving total parenteral nutrition. Pediatrics 1979: 63: $1111-5$

20) Wirtschafter D). Ermoilla R. Harris H. Cassady (i. Neonatal intrahepatic cholestasis. (Abstract.) Pedicatr Res 1975: 9: 310 .

21 Peden VII. Witzleben (C.. Skelton MA. Total parenteral nutrition. (Letter.) J Pediatr 1971: 78: 180.

22 Brown MR. Putnam TC. ('holestasis associated with central intravenous nutrition in infants. $N Y$ State $J$ Med 1978: 78: 27-30.

23 Nakai H. Landing BH. Factors in the genesis of bile stasis in infancs. Pédiatrics 1961: 27: 30)-7.

2f Popper H. Mechanism of cholestasis. In: Bianchi (i. (jerok W. Sickinger K. eds. Liver and bile. Lancaster: MTP Press. 1977: 189-201.

25 Johnson JD. Albritton WL. Sunshine P. Hyperammonemia accompanying parenteral nutrition in newborn infants. J Pediatr 1972: 81: 154-61.

26 (irout JP. Cox ('E. Kleinman LM. Maher MM. Pittman MA. Tangrea J et al. Serum hepatic enzyme and bilirubin elevations during parenteral nutrition. Surg (ivnecol ()bstet 1977: 145: 573-80).

27 Vileisis RA. Inwood RJ. Hunt C.E. Prospective controlled study of parenteral nutrition-associated cholestatic jaundice: effect of protein intake. $J$ Pediatr 198(): 96: 893-7.

28 Hughes CA. Dowling RH. Speed of onset of adaptive mucosal hypoplasia and hypofunction in the intestine of parenterally fed rats. (lin Sci 1980: 59: 317-27.

29 Hughes $C A$. Prince A. Dowling RH. Speed of change in pancreatic mass and in intestinal bacteriology of parenterally fed rats. (lin Sci 1980): 59: 329-36.

30) Hughes (A. Breuer RS. Ducker DA. Hatoff DE. Dowling RH. The effect of cholecystokinin and secretin on intestinal and pancreatic structure and function. In: Dowling RH. Riecken EO. Robinson JWL. eds. Intestinal adaptation and its mechanisms. Lancaster: MTP Press, 1982: 435-50.

31 Lucas A. Bloom SR. Aynsley-Green A. Development of gut hormone responses to feeding in neonates. Arch Dis Child 1980: 55: 678-82.

32 Domschke W. Domschke S. Bilirubin metabolism and bile secretion: hormonal regulation. In: Bianchi $L$. Gerok W. Sickinger K. eds. Liver and bile. Lancaster: MTP Press. 1977: 167-76.

33 Watkins JB. Szczepanik P. Gould JB. Klein P. Lester $R$. Bile salt metabolism in the human premature infant: preliminary observations of pool size and synthesis rate following prenatal administration of dexamethasone and phenobarbitol. Gastroenterology 1975: 69: 7()6-13.

34 Gimmon Z. Kelley RE. Simko V. Fischer JE. Total parenteral nutrition (TPN) solution induces increase in lithogenicity of bile in the rat. (Abstract.) Gastroenterology 1980: 79: 10121. 